\title{
Els Secrets d'agricultura (1617) de Miquel Agustí en el context dels llibres agronòmics europeus
}

\author{
Xavier Luna-Batlle \\ Grup de recerca Scripta i projecció dialectal (Universitat de Barcelona) \\ xlbatlle@gmail.com
}

Rebut: abril de 2015

Acceptat: octubre de 2015

\section{Resum}

El llibre de Miquel Agustí, Secrets d'agricultura (1617), s'analitza contrastant-lo amb els textos agronòmics europeus anteriors i coetanis per tal de veure'n les fonts i el context ideològic i textual. Es mostren alguns resultats de l'acarament amb una de les fonts principals, el llibre francès La Maison rustique de Charles Estienne i Jean Liébault, i s'observa com Agustí en treu bona part del contingut i de la redacció. Es constata que en l'obra d'Agustí no hi ha la influència ni de l'obra agronòmica de l'espanyol Alonso de Herrera ni la del text més avançat de l'inici del s. XVII, el Théâtre d'Agriculture d'Olivier de Serres. De la font principal provenen alguns gallicismes, dins d'una obra que conté també interessants mots genuïns, ben útils per a la història de la llengua i en particular dels parlars catalans del nord-est.

Paraules clau: Miquel Agustí; segles XVI i XVII; agricultura; textos agronòmics europeus; traducció; llengua catalana; gal-licismes; dialectalismes.

Resumen. Los Secrets d'agricultura (1617) de Miquel Agustí en el contexto de los libros agronómicos europeos

El libro de Miquel Agustí, Secrets d'agricultura (1617), se analiza en contraste con los textos agronómicos europeos anteriores y coetáneos para observar las fuentes y el contexto ideológico y textual. Se muestran algunos resultados de cotejar la obra de Agustí con una de sus fuentes principales, el libro francés La Maison rustique de Charles Estienne y Jean Liébault, y se observa cómo se extrae de él buena parte del contenido y de la redacción. Se constata que en la obra de Agustí no hay influencia de de la obra del agrónomo español Alonso de Herrera ni del texto más avanzado de inicio del siglo xviI, el Théâtre d'Agriculture de Olivier de Serres. De la fuente principal proceden algunos galicismos, dentro de una obra que contiene también interesantes palabras genuinas, muy útiles para la historia de la lengua catalana y en particular de sus hablas del noreste.

Palabras clave: Miquel Agustí; siglos XVI y XVII; agricultura; textos agronómicos europeos; traducción; lengua catalana; galicismos; dialectalismos.

Abstract. The Secrets d'agricultura (1617) by Miquel Agustí in the context of European agronomic books

Miquel Agustí's book, Secrets d'agricultura (1617), is discussed in contrast to previous and contemporary European agronomic texts to observe ideological sources and textual contexts. The article shows some results of comparing the work of Agustí with one of its main sources, 
the French book La Maison Rustique by Charles Estienne and Jean Liébault, and how much of the content and wording is extracted. It is found that in the work of Agustí there is no influence of the work of the Spanish agricultural book by Alonso de Herrera and the most advanced early seventeenth-century text, the Théâtre d'Agriculture by Olivier de Serres. Some Gallicisms come from the French book; nevertheless, it also contains interesting genuine words, which are very useful for the history of the Catalan language and particularly its northeastern dialects.

Keywords: Miquel Agustí; $16^{\text {th }}$ and $17^{\text {th }}$ centuries; agriculture; European agronomic texts; translation; Catalan language; Gallicisms; dialectalisms.

\begin{aligned} & \multicolumn{2}{c}{ Sumari } \\ & Introducció Antoine Mizauld i Olivier de Serres \\ & Gabriel Alonso de Herrera i Els Secrets, el context i les fonts \\ & l'Agricultura general (1513) Gal-licismes i castellanismes \\ & $\begin{array}{r}\text { rustique de Charles Estienne } \\ \text { i Jean Liébault a la França } \\ \text { del segle XVI }\end{array}$ Mots genuïns no literaris \\ &\end{aligned}

\section{Introducció}

L'article d'Emili Giralt «Les fonts dels Secrets d'agricultura, casa rústica i pastoril (1617) de Miquel Agustí» del 2002 posa els fonaments per conèixer l'origen dels continguts d'un dels tractats de temàtica pagesa més importants i extensos escrits en català. I és un tema complex en tots els llibres agronòmics, des dels més clàssics, com segurament ho és en tots els tractats que versen sobre una activitat tècnica o econòmica tradicional. En un article anterior (Luna-Batlle, 2013) vam llistar els aspectes més interessants del llibre tot fent veure que calia desenvolupar-los ja que només albirem de moment algunes de les explicacions que ens permetran fer-nos una idea de conjunt de l'obra en el seu context. Una obra de dimensions relativament grans que va tenir una recepció notable i duradora: «[fou] fins a èpoques ben recents, mercès a les seves múltiples reedicions en castellà durant els segles XVII i XVIII, el manual de referència del camp català en agronomia, medicina pràctica i manescalia» (Cifuentes, 2001: 294). Una prova de la seva popularitat és que es conegué com «el llibre del Prior» (i així se l'esmenta al Diccionari Aguiló o al llibre Lo jardiner hortolà y florista signat pels pares Caputxins de Catalunya, Barcelona, 1852), una expressió amb connotacions de prestigi. L'autor, banyolí de naixença, ocupà aquest càrrec al convent de Sant Joan de Perpinyà, referència que el lector veia ben destacada a la portada (acompanyada d'una imposant i ornada il-lustració amb la creu de vuit puntes de l'orde de Malta): «per fra Miquel Agustí, Prior del Temple de la fidelíssima vila de Perpinyà, de la religió del Hospital de Sant Joan de Hierusalem, natural de la vila de Banyoles, bisbat de Gerona». 
Miquel Agustí, nascut a Banyoles, viu al Rosselló força temps i a Barcelona es publica la seva obra per primera vegada el 1617. La segona edició de l'obra d'Agustí apareix a Perpinyà el 1626, traduïda pel mateix Prior al castellà nou anys després de la primera i única edició en català. De la vida de Miquel Agustí no en sabem pràcticament res més i ens hem de basar en el mateix text per esbrinar-ne la gestació.

Les fonts dels Secrets és un dels temes més complexos que se'ns posen al davant quan mirem d'entendre el text en el seu context. Emili Giralt (2002) fa un panorama lacònic de les fonts explicitades en els Secrets partint de la «nòmina» de 84 autors que ofereix Agustí, llista que va des dels clàssics fins als coetanis, responent a la declaració d'intencions de la portada, on es diu que el tractat és «recopilat de diversos autors, antichs y moderns, de llengua llatina, italiana y francesa en nostra vulgar llengua catalana».

Cal remarcar que en l'elenc no hi ha cap autor castellà. I se'ns fa estrany sabent que el famós llibre d'Alonso de Herrera, Agricultura general, estampat per primera vegada el 1513, una mica més de cent anys abans que els Secrets, tingué un èxit notable a l'Europa de l'edat moderna, no només a l'Espanya del moment. L'intent de comprendre el llibre de Miquel Agustí ha de mirar d'escatir per què beu d'unes fonts i no d'unes altres que també tenia a l'abast. A la llista d'autors sí que s'esmenta, i apareix molt assíduament als marges al llarg de tot el tractat, el llibre agronòmic francès més famós del cinc-cents, L'agriculture et maison rustique de Charles Estienne i Jean Liébault. Caldrà esbrinar també el perquè de la segona gran absència, la d'un altre llibre francès, també de gran envergadura, Le Théâtre d'agriculture et mesnage des champs d'Olivier de Serres, que apareix just a l'inici del sis-cents, setze anys abans que el d'Agustí. Aquests tractats, amb els d'Antoine Mizault, són les obres agronòmiques de més pes de l'entorn bibliogràfic més proper a Miquel Agustí. I encara que en un segon pla, sí que veiem esmentat en els Secrets amb una relativa freqüència el famós Pal-ladi, que es refereix a la llarga família de versions que parteixen de l'Opus agriculturae del Rutili Pal-ladi dels segles IV-V, un text molt modificat durant la baixa edat mitjana i una obra de gran circulació i prestigi (Cifuentes, 2001: 289). De la relació d'Agustí amb els Pal·ladis no ens n'hem ocupat encara, però és possible que n'hi hagi rastres.

\section{Gabriel Alonso de Herrera i l'Agricultura general (1513)}

L'Agricultura general de Gabriel Alonso de Herrera, que apareix per primer cop el 1513, és el primer tractat agrícola escrit en llengua vulgar en el Renaixement europeu. Té catorze edicions conegudes al segle XVI a Espanya, fou traduït al llatí, al francès i a l'italià. Gabriel Alonso de Herrera va néixer a Talavera de la Reina entre el 1460 i el 1470, va viure a Granada en el període immediat a la conquesta de la ciutat als àrabs el 1492. Germà d'Hernando Alonso de Herrera, un notable autor renaixentista castellà admirador de l'obra de Lorenzo Valla, Gabriel adquirí fama ben aviat. Segons Consolación Baranda (1989: 96-97) «En esta ciudad [Granada], tenía fama de experto en cuestiones agrícolas ya en 1502; hay 
varios documentos en los que se alaba la calidad de las huertas que cuidaba. Viajó por Italia y Francia, a fin de recoger información y adquirir conocimientos prácticos para este libro. [...] sus relaciones familiares y personales les sitúan [tots dos germans] en el círculo intelectual más selecto y avanzado del humanismo de su época. Su obra nace ligada al movimiento de renovación profunda de los marcos intelectuales y a las preocupaciones reformadoras de Cisneros».

L'estil de Gabriel Alonso de Herrera és culte, amb un discurs llarg i elaborat, amb hipèrbatons classicitzants; Baranda (1989) el considera d'indubtable valor literari.

Una mostra ens il·lustrarà molt bé el seu estil:

\section{Cap. IV. De los sitios}

Dicho he brevemente qué tal ha de ser la tierra para las viñas, queda decir del sitio, y estos son de dos maneras: o altos o llanos. En los llanos las viñas llevan más fruto que en los altos, mas es muy mejor el vino de los altos, más olorosos y de más dura. En los montes las viñas que están acia el cierzo da más fruto que las que están acia mediodía, porque el cierzo, aunque de su naturaleza es seco por ser frío, las mantiene más frescas, y por esso dan más frutos, excepto en lugares donde el frío es muy demasiado. Las viñas que estan acia mediodía, dan mejor vino por tener mejor maduradero y la uva se tuesta más y no se pudre tanto. Los valles, mayormente si son hondos, es el peor de quantos sitios ay para viñas, porque pudren mucho la uva y la tienen muy verdiona, sin color y sin sabor, y aunque en semejantes lugares cargan mucho las cepas, vale más poco y bueno en lo alto que lo mucho del valle, salvo si los valles son acia el sol.

Cap. V. Qué tal ha de ser el sarmiento, o qualquier planta para poner, y como se escoge.

[...] Y por esso el que pudiere poner jaén, no ponga tortozón; y el que alvilla, no jaén, digo considerando los lugares, que a cada uno pertenece, según que se ha dicho, y en cada linaje deve escoger lo mejor dél, y vale mas trabajar una vez en buscar buenas plantas, que trabajar en quitar o adobar las que no sabiamente buscó.

El contrast amb el d'Agustí és clar: aquí la redacció és molt més lacònica, sense afany d'elaborar les frases, un discurs pràctic i gens classicitzant, poc matisat:

No convé de plantar las vinyas de moltes sorts de rahims, perquè los rahims, los uns madúran abans que los altres, y axí no vénen tots a un temps, que los uns són primarenchs y los altres tardans, y per ço no convé plantar les vinyas de diverses maneres de rahims, perquè los rahims primarenchs y los tardans són veremats tots plegats. Axò és la causa que tants vins se gàstan. Y també mesclar los rahims blanchs ab los negras, que són de naturalesa contrària. Y axí mateix dels negras. Són differents los uns dels altres: los uns són rosos, altres negras, altres blanquinosos; y l'altre dols, l'altre aspre, l'altre agre; lo hu durable, y l'altre no; lo un vi és millor vell, que no nou, l'altre encontinent és fet; lo hu requer una manera de govern, y l'altre indiferent. Y axí si voleu fer bon vi plantau las vinyas de unas sort de rahims, y de cada sort de rahims, feu vòstron vi.

Lo vi moscat de la vinya moscada.

Lo vi castellà de la vinya de rahims castellans. 
Lo vi blanch de vinya de monestrells blanchs, y de pansas.

Lo vi malvasia, de vinya de malvasia.

Lo vi trobat, de vinya de rahims trobats.

Lo vi grech, de rahims grechs.

Lo vi macabeu, de rahims de vinya de macabeus.

El repertori és ben interessant per a la història agrària, ens dóna notícia de les varietats del raïm en temps d'Agustí, però també exemplifica un estil ben diferent al del text castellà.

Antonio Saltini, a la seva Storia delle scienze agrarie, descriu el llibre d'Herrera amb elogis notables: el titlla de text coherent, amb una extraordinària capacitat de síntesi, amb un ordre expositiu simple, orgànic i nítid. Té l'habilitat del filòleg i el gust humanista, amb citacions escrupoloses de les fonts clàssics, que integra amb anotacions sobre l'agricultura coetània. Coneix bé i de primera mà l'agricultura àrab com també alguns clàssics de l'agronomia en àrab. I finalment ens diu que és la primera manifestació, en la cultura agronòmica europea, de l'empirisme pràctic amb el qual la ciència agrària iniciarà el camí de la pròpia renovació (Saltini, 1979: 215).

Seguint encara Saltini, Gabriel Alonso de Herrera és el primer en la història de la literatura agronòmica que fa la distinció entre fer el vi amb la rapa (el vi negre) o separant-la'n (el vi blanc) (Saltini, 1979: 227). Saltini també ens diu que el procediment que dóna Gabriel Alonso de Herrera de rentar les bótes abans de la verema amb aigua salada és encara en ús a les illes Lipari, on posen les bótes alineades al moll i les omplen cada matí d'aigua de mar fresca fins que les dogues arriben al punt de reinflar-se suficientment perquè no perdin suc (Saltini, 1979: 227), una observació que dóna idea de l'amplitud de les seves referències i coneixements. Però d'Herrera no hem trobat rastre fins ara en l'obra d'Agustí.

\section{La Maison rustique de Charles Estienne i Jean Liébault a la França del segle XVI}

L'obra agronòmica de Charles Estienne, després ampliada amb l'aportació de Jean Liébault, es caracteritza en primer lloc per ser una compilació successiva, una sèrie llarga d'obres que van acumulant material fins a arribar a un volum de dimensions importants.

Ch. Estienne és membre d'una notable família, la saga més important d'impressors de la França de la seva època. A París, Ch. Estienne edita el 1535 De re hortensi libelus, el 1536 Seminarium et plantarium fructiferarium, i Vinetum el 1537. Tres obres de temàtica agronòmica publicades en tres anys successius. Aquestes tres obres es reuneixen en el Praedium rusticum el 1554, obra que es traduí al francès amb el títol de L'Agriculture et Maison rustique el 1564, el mateix any en què mor Charles Estienne. Una nova edició força augmentada apareixerà el $1570 \mathrm{amb}$ uns prolegòmens del metge lionès Jean Liébault. I el 1586 a l'autoria d'Estienne, s'hi afegeix aquest metge, parent seu, i s'hi observa un augment considerable del contingut del llibre precedent, un gran volum de 
temàtica no només agrícola, sinó mèdica, pecuària, venatòria, organitzat en set llibres (és a dir set parts). De l'edició de 1586 n'hi ha un exemplar a la Biblioteca de Catalunya i de la de 1602, molt semblant, un a la Biblioteca de la Universitat de Barcelona procedent de l'antic convent de Sant Josep, indicis que permeten intuir que aquestes obres agronòmiques franceses eren força conegudes a Catalunya. Antonio Saltini, a la seva Storia delle scienze agrarie, fa una valoració de l'obra d'Estienne i Liébault ben diferent respecte a la de Gabriel Alonso de Herrera: en els francesos hi ha asistematicitat, acumulació desendreçada, manca de coherència en l'organització del material. El titlla de caleidoscopi, «elenchi interminabili di essenze affastellate senza ordine» (Saltini, 1979: 258). En algun cas un desordre clar, segons Saltini: «Del tutto disorganica l'ultima elencazione, che raccoglie piante prive di qualsiasi carattere botanico comune, dal ginepro alle palme, dall'edera all'ulivo, dai capperi ai pini» (Saltini, 1979: 258). Finalment, aporta proves diverses de la «incoerenza del piano dell'opera». Val a dir que Saltini no té en compte l'evolució acumulativa de l'obra que s'observa contrastant les diverses edicions, com hem assenyalat, i que pot explicar en part el seu desordre.

S'ha indicat des dels primers comentaristes (Argemí, 1985) que L'Agriculture et Maison rustique d'Estienne i Liébault és la font més important d'Agustí i ell mateix indirectament així ho deixa entendre: és amb una gran diferència l'autoria més esmentada als marges del llibre, generosos amb referències a tota mena d'obres. De tota manera, podem assenyalar un matís important. Els esments dels marges que indiquen només «Esteve» són 88, mentre els que indiquen «Esteve i Llibaut» són només 6. Sembla clar que Agustí tingué al davant almenys dues obres, la redactada només per Charles Estienne, a la qual es refereix majoritàriament, i la més tardana, la redactada per Estienne i per Liébault.

Però tanmateix es fa una primera constatació a l'hora d'acarar l'obra francesa amb la catalana: l'estructura interna és molt diferent. L'Agriculture francesa està formada per set llibres, que s'ocupen dels temes següents (les diferències entre l'estructura de l'obra primerenca d'Estienne i la posteriors d'Estienne i Liébault són molt poc rellevants):

1) La casa. L'ofici d'agricultor. Coneixements climatològics i astrològics. L'agricultura. Animals i espais on han d'estar-se.

2) L'hort. Productes d'horticultura. Herbes medicinals. Flors. Herbes aromàtiques.

3) Fruiterar. Arbres de conreu: fruiters, olivera. Manufactura d'olis de diversa composició.

4) El prat. L'estany i les basses. Peixos d'estany.

5) Terres de conreu. Mesura de les terres. Conreu dels grans (blat i altres). Llegums, arròs, lli. El pa. La pastisseria.

6) La vinya.

7) La garenne o llocs de caça reservats, en particular on es deixa que criïn els conills. Els animals de caça. La falconeria. Els ocells.

Agustí organitza el contingut del seu llibre d'una manera ben diferent, i en tres llibres i no pas set, que s'ocupen dels temes següents: 
1) «De les coses té de fer y saber lo pare y mare de la casa de agricultura». Hort i hortalissa. Herbes medicinals. Les flors. Els fruiters. Els empelts dels arbres. Animals perjudicials per als arbres, particularment els insectes. El bosc. El prat. Els grans.

2) La vinya. El vi. La destil-lació. La conserva d'herbes, de fruites. La mesura de la terra (canejar).

3) Lloc adequat i construcció de la casa. Els animals. Les abelles. Els cucs de seda. L'astrologia. Els insectes perjudicials. Els peixos.

Una diferència que també salta a la vista d'entrada és que Agustí comença moralitzant i instruint el pater familias (com també la mater familias); en canvi, Estienne comença per la casa entesa com a habitatge, de la tria de l'espai on establir-se, tema que Agustí desplaça a la tercera part. ¿Podem aixecar la hipòtesi que hi ha una marcada intenció moralitzant sense abandonar la intenció tècnica?

L'èxit dels francesos és enorme al segle xvI. Es tradueix a diverses llengües i Saltini fa veure la connexió de l'obra d'Estienne amb l'Opus ruralium commodorum del bolonyès Pietro di Crescenzi, un dels llibres agronòmics més importants de l'Europa medieval, tractant-lo d'epígon, i afirmant que si Crescenzi, a l'alba del segle XIV, no era possible que pogués diferenciar la frontera entre la biologia escolàstica i la pràctica empírica, a la segona meitat del segle XVI som ja en l'època més fèrtil de l'intent de l'home de penetrar amb les armes de la raó els misteris de la natura (Saltini, 1979: 259). Saltini, però, considera que hi ha una excepció singular que ja no prové de la tradició: el capítol dedicat a la nicotiana és la primera pàgina de la literatura agronòmica que es dedica a analitzar les característiques de la planta acabada d'arribar del Nou Món, destinada a assumir un paper rellevant en el paisatge agrícola i comercial dels segles successius. Estienne i Liébault, doncs, representen la resistència d'una ciència que ja havia entrat en declivi i que no havia fet el salt a la nova ciència moderna. I l'obra de Miquel Agustí és fidel a aquesta tradició recollint massivament el contingut d'Estienne i Liébault, molt sovint fent-ne la traducció directa. Per donar-ne només un exemple, els folis d'Agustí que van del 106 al 108 són una traducció literal de l'obra d'Estienne i Liébault amb una única indicació d'aquesta font a l'inici del marge del foli 106 recto on llegim «Carles Esteve y Joan Llibaut».

\section{Antoine Mizauld i Olivier de Serres}

Un autor també molt citat per Agustí, encara que no tant com els anteriors, és Antoine Mizault (1520-1578). És un astròleg i metge de Montluçon, amant de les ciències ocultes i de l'alquímia (usa sovint el mot secret per a referir-se a tota mena de pràctiques, màgiques o no), i autor de nombroses obres en llatí sobre aquestes temàtiques i sobre botànica, amb traduccions a diverses llengües, i de qui Emili Giralt diu que «és potser l'autor de més relleu entre els innombrables creadors de literatura pseudocientífica entorn a "secrets", "misteris" o "arcans". Mizauld és la segona font en importància i el més gran responsable — però no l'únic_ del "secretisme" que caracteritza l'obra de l'agrònom català» (Giralt, 
2002: 338). En efecte, en una primera aproximació a aquest autor, amb 54 esments als marges del llibre d'Agustí, trobem que al capítol «Secrets per a saber en quin temps se han de sembrar los horts o camps» (f. 15v-16r) que té al marge la referència a «Mizaldo» és tret de Le jardinage, de 1578, tal com ho prova l'acarament d'aquestes ratlles:

\begin{tabular}{|c|c|}
\hline Mizault (1578), f. 20 & Agustí (1617), f. 16 \\
\hline $\begin{array}{l}\text { Entre les autheurs grecs d'agriculture, } \\
\text { il y en a qui conseillent de semer, la lune } \\
\text { estant en croissant, depuis la quarte jusques } \\
\text { à ce qu'elle soit pleine, pendant qu'elle est } \\
\text { sous la terre. [...] } \\
\text { [...] le fient fera la terre plus abondante en } \\
\text { suc, et plus ouverte à recevoir l'eau qui ira } \\
\text { jusques aux racines; et l'eau nourrira, et } \\
\text { entretiendra tout comme d'une mammelle. }\end{array}$ & $\begin{array}{l}\text { A-y alguns escriptors grechs de coses de } \\
\text { camps que acostumen sembrar quant la lluna } \\
\text { va crexent, ço és, quant és al segon quart } \\
\text { fins fa lo ple, mentre és la lluna bax de terra. } \\
{[\ldots]} \\
{[\ldots] \text { lo fems farà la terra grassa y la }} \\
\text { esponjarà per a que la aygua se empape en } \\
\text { la terra més fàcilment, participant-ne les } \\
\text { raels com la aygua sia com una mamella que } \\
\text { cria y fertiliza totes les coses. }\end{array}$ \\
\hline
\end{tabular}

En aquest mateix foli veiem com Agustí arrossega les referència a autors clàssics que apareixen a la font del text: Mizauld esmenta «les autheurs grecs» $\mathrm{i}$ Agustí igualment diu «alguns escriptors grechs de coses de camps». En un altre punt, Mizault parla de Columel-la, i Agustí també ho repeteix per bé que en aquest cas, el del foli que hem esmentat, Columel-la no apareix al marge. Les referències indirectes d'aquest estil són freqüents i cal separar, doncs, les fonts directes de les referències mediatitzades per aquestes fonts; les directes són en nombre molt més reduït que la vuitantena de la llista que presenta a l'inici del llibre i que hem comentat abans.

Ben lluny ideològicament — que no pas temporalment— de Mizauld trobem Olivier de Serres, amb Le Théâtre d'agriculture et mesnages des champs, de 1600, que marca a França i a Europa un nou període dels textos agronòmics. L'autor és un ric propietari rural del Vivarès, comarca del Llenguadoc, al Massís Central, interessat en la productivitat de les seves extenses terres en un medi generós amb l'agricultura, coneixedor de tot França i més enllà, que va a París i comenta amb detall com es conreen allà certes plantes. Un excel-lent recopilador d'informació agrària de tota mena (Goudin, 2001). Donarem només un exemple, el dels vins, que ens indica l'exuberància informativa de Serres:

[...] les excellents vins blancs d'Orléans, de Couci, de Loudun en Languedoc, d'Anjou, de Beaune, de Joyese, de l'Argentière, de Montreal, de Lambras, de Cornas en nostre Vivaretz. De Gaillac, de Rabastenc, de Nerac, d'Aunix, de Grave. Les friants vins-clerets de Cante-perdrix, terroir de Beaucaire, de Castelnau, de Moussen-Giraud, de Baignolz, de Montellimar, de Villeneuve-de-Berc, de Tournon, de Ris, d'Ay, d'Arbois, de Bourdeaux, de la Rochelle et d'autres diverses sortes, croissans ès provinces de Bourgogne, d'Anjou, du Maine, de Guyenne, de Gascongne, du Languedoc, du Dauphiné, de la Province. Sur tous lesquels vins paroissent les musquats et blanquetes de Frontignac et Miravaux en Languedoc, 
dont la valeur les faict transporter par tous les recoins de ce royaume. (ed. 1600: 145; ed. 2001: 271-272)

Manifesta interès per construir repertoris, força extensos. En relació amb les menes de figues, malgrat que diu que no les anomena totes, ens diu:

Es endroits de ce royaume où la figue croist gaiement, on faict cas de celles qu'on nomme ainsi: aubicons, bourjassotes, blanquetes, brunessenques, quotidianes, oeil-de-perdrix, blavetes, coucourelles, bouvaux, douces, hospitalières, coquines, rousseaux, pel-dure, marseilletes, angéliques, qui sont blanches, longues et grosses, pourquines, noires et petites; pour brefveté obmettant les autres. (ed. 1600: 698; ed. 2001: 1040-1041)

Hi veiem les «burjassotes», una mena de figa que té l'origen del nom a la població valenciana de Burjassot i que Joan Veny (2001: 81) ha estudiat en les múltiples formes que ha adoptat el significant. Que aparegui en Olivier de Serres corrobora, amb una altra dada, el que diu Joan Veny: que el nom català d'aquesta mena de figa traspassà les fronteres de la llengua catalana. I en el nostre Agustí no apareix aquesta mena de figa; de fet només parla de dues menes de figa: les blanques i les negres, mentre que Olivier de Serres n'esmenta 17 i encara afegeix «pour brefveté obmettant les autres», com hem vist. Les diferències salten a la vista.

Però el més interessant de Serres, i que contrasta fortament tant amb Mizauld com amb Agustí, és la crítica directa a les tradicions supersticioses. Serres n'esmenta un reguitzell, d'aquestes supersticions, a benefici d'inventari. Per exemple aquestes: per evitar que els ocells no es mengin les llavors es diu que podem arruixar-les amb aigua preparada amb crancs, banya de cérvol o ivori barrejat amb fulles de xiprer; per evitar que les rates es mengin el gra podem posar-hi cendres de guineu o de fagina; perquè no es faci malbé el vi podem escriure a la bóta la frase «Gustate et videte, quod bonus est Dominus»; per combatre les males herbes de l'hort podem fer que hi passi una dona amb la menstruació. De la llarga llista d'idees d'aquesta mena assevera que es tracta de divertiments $\mathrm{i}$ d'incertituds ridícules, i afegeix: «que nostre père-de-famille quittant toutes ces vanités, quoiqu'antiques, s'arrestent à ce que par expérimentée raison et longue pratique, verra estre bon à ses affaires et ouvrages» (ed. 1600: 47; ed. 2001: 134).

Aquestes supersticions típicament medievals, moltes provinents dels clàssics, encara tenen el favor i el suport del renaixentista Herrera, que comença dient, per exemple, un «dicen que» però continua posant fe en tal cosa amb el suport d'un altre exemple que dóna per provat i que és evident que prové igualment de la tradició diguem-ne precientífica que es remunta als textos més antics coneguts. L'exemple següent aixeca avui un somriure, però no creiem que fóra aquesta la intenció d'Herrera:

Dicen que si la hortaliza tiene piojuelo, que una muger quando tiene su flor dé dos o tres vueltas descalza en rededor de la era y caerá todo el piojuelo. Y no és de 
maravillar, pues tanta es en aquel tiempo su ponzoña que mancha un espejo si a él se mira y aun muchas veces le quiebra, como por experiencia se vee, pues no es mucho que mate el piojuelo (Herrera: 271)

Olivier de Serres és a l'inici, doncs, d'un període realment nou i modern en la història dels textos agronòmics europeus, i Miquel Agustí en prescindeix.

\section{Els Secrets, el context i les fonts}

Emili Giralt, entre altres historiadors, ens ha fet veure els valors del llibre d'Agustí, que en té de notables, però també que «el Prior Agustí, amb la seva dèria d'exhibir lectures erudites, accepta sense crítica les fantasies contingudes en la literatura pseudocientífica emparentada amb l'astrologia, la màgia i el secretisme propis de la geopònica de l'hel-lenisme tardà» (Giralt, 2008: 356a). En efecte, hi ha passatges de focs d'artifici dedicats als clàssics.

Els capítols titulats «Discurs breu sobre la invenció, naturaleza, facultat, differencias y necessitat del vi» i els següents, «Com lo beure de tots los animals és la aygua», «Què cosa és vi» $\mathrm{i}$ «Los inventós del vi», que ocupen dos folis per les dues cares, corresponen a una traducció gairebé literal dels d'Estienne i Liébault «Discours passager sur l'invention, nature, facultez, differences et necessité du vin», «Le boire commun de tous animaux est l'eau», «Qu'est-de que vin» $\mathrm{i}$ «Les inventeurs du vin». La traducció tira pel dret sense immutar-se quan el text francès diu: «Quant à moy je crois que...»: Agustí també fa «Quant a mon parer...», sense canviar de persona gramatical. Més encara, al text francès no hi ha al marge cap referència als autors d'on procedeixen les idees i Agustí anota al marge Nicander Colophovius, i cinc ratlles més avall, «Properce», que s'esmenten també dins del text. Ginys textuals per al lluïment? Tindria potser més interès saber, si poguéssim interrogar el Prior, per quina raó de tots aquests llargs passatges traduïts literalment, hi ha un únic fragment que no es tradueix i es condensa amb una explicació banal sobre el significat de la llambrusca. El text francès que no apareix en Agustí diu, després d'esmentar la llambrusca:

Mais que les premiers peres n'ont si tost cognu l'usage du vin. Car en l'Amerique, Floride et pays nouvellement trouvez, il y a grande quantité de vignes qui y croissent luxurieusement et en affluence, sans art et aucune industrie des hommes, jaçoit que l'usage du vin soit encor incogneu aux habitants de ce pays. Platon en son Cratile dit que le vin est nommé en grec oinós, [...] c'est à dire, jugement, cogitation, [...], parce qu'il remplist l'entendement de jugement, cogitation, d'autant que par sa celerité il restaure les esprits, dont il fortifie, non moins l'ame que le corps, [...]: Aucuns aussi disent que les grecs appellent oinós [...] c'est a dire, proffit, utilité, parce qu'il et infiniment utile.» (p. 724)

Sembla clar que aquí s'amaguen dues coses: que a Amèrica hi havia vinya salvatge i se sabia (divulgar això no tenia interès econòmic, pràctic o científic?) i que el vi, segons els estimats clàssics (Plató), creien que afavoria el pensament i 
el judici, era profitós i infinitament útil. En aquest salt en la traducció amaga una referència profana, per un banda, i la lloança del vi, per una altra. Si el fragment francès diu:

D'où vient qu'il reveille l'entendement, apporte courage aux languissans, recree et resjouyst l'esprit à raison dequoy dit Homere, les Dieux ont donné le vin aux hommes, afin de chasser leur soucis et fascheries. Et Socrates au convive de Platon, louë le vin pris moderément au banquet, parce qu'il excite à vertu et rend l'ame plus alacre ['més volenterosa'] à faire ses functions. (Estienne i Liébault: 727);

Agustí en tradueix només això: «D'on ve que ell desperta son enteniment y dóna forsas als flachs, recrea y reviva les forses.» (f. 108v). Per què no tradueix la referència homèrica que els déus havien donat el vi als homes a fi de deslliurar-los de maldecaps i preocupacions?

En resum, podem dir amb Emili Giralt (2002) que l'elenc de la vuitantena d'autors dels quals Agustí diu que treu el contingut del seu llibre és més per impressionar el lector o per donar prestigi a l'obra que no pas per altra cosa. No és cert que Agustí hagi llegit de primera mà tots els llibres que dóna com a font de la seva obra. Més enllà encara, l'acarament amb el llibre d'Estienne i Liébault ens revela que les citacions d'autors que Agustí es vanta de conèixer de fet ja són en el llibre francès, i doncs amb la traducció s'arrosseguen sense que Agustí ens informi que les referències les treu d'aquell llibre.

No és estrany que aquest tarannà, sigui d'Agustí o sigui de l'època, es repeteixi quan en la primera versió castellana (Perpinyà, 1626) s'incorpora un tractat sobre la cacera del llop (un tractat complex, amb il-lustracions) sense dir-ne l'autor quan es descobreix que es tracta del tractat que s'afegí a l'edició de 1570, un llibre independent estampat el 1669 per François Estienne, del capità de la marina Jean de Clamorgan que s'afegeix en aquest llibre per la raó, segons es llegeix a la coberta, que és «necessaire à la maison rustique».

I avançant per aquests camins, hom s'adona que una cosa és que Agustí digui al marge «Esteva» i una altra de diferent que digui «Esteva i Llibau metges» com ja hem comentat. Fent el contrast en els apartats de les herbes medicinals resulta que la font directa és el llibre que escrigué Estienne (1564) tot sol, molt més breu que no pas la sèrie posterior dels Estienne i Liébault.

En contrast amb les nombroses pàgines de traducció literal — l'acarament exhaustiu encara està per fer-o d'altres consistents en versions més o menys adaptades, no podem oblidar que n'hi ha, no pas poques ni de temes menors, que semblen sincerament elaborades pel mateix Agustí. A Luna-Batlle (2013) vam recollir la desena de temes que molt probablement Agustí redacta de primera mà. Hem de descartar de manera contundent l'opinió precipitada i sense fonament del que ha escrit que «pese a que Agustí presenta su obra como pròpia, la realidad es que se trata de una copia casi literal de L'agriculture et maison rustique del médico francés Charles Estienne y su yerno el espagirista Jean Liébault» que Núñez (2007-2008: 202) recull d'un treball aliè, sense matisar gens, com tampoc 
no és cert que «La obra contaba con un contenido similar al de otros textos contemporaneos como la Agricultura general de Alonso de Herrera o Le Théâtre d'Agriculture et Mesnage des Champs de Olivier de Serres» (ibídem: 202).

El que acabem d'esmentar només són uns apunts a les fonts del llibre d'Agustí; el tema s'eixampla per diversos camins i alguns estan per encetar. Maria Antònia Martí Escayol ha dut a terme també una feina contrastiva i ens ha fet veure les coincidències entre el text agronòmic català del segle XV de la Biblioteca Nacional de França, a París. D'aquest text, en tenim també una còpia manuscrita de final del xv, que ja han editat Maria Rosa Raich i Thomas Capuano, i que jo mateix he tornat a editar el $2011 \mathrm{amb}$ el títol Libre de plantar vinyes e arbres. Martí (2012) ha trobat pistes de la connexió de tots dos textos. Posar al descobert les xarxes d'influències en els Secrets és una feina ingent.

\section{Gal-licismes i castellanismes}

Passem a alguns exemples del rendiment filològic que podem treure d'Agustí tenint en compte les fonts i que ens permeten contextualitzar la informació filològica en relació amb determinats mots.

Sabent que l'obra d'Agustí tradueix i versiona l'obra dels francesos Estienne i Liébault, no pot sorprendre que hi trobem un bona llista de gal-licismes. Ja ho havia previst Montserrat Barri (1999) en estudiar els gal-licismes del català, i hi recull alguns casos extrets de l'obra del banyolí. Però la llista completa encara està per fer i ara només en comentaré alguns.

ayre (de terra) «Lo pomer se fa en qualsevol ayre de terra y vol la terra grassa y humida» (f. 54v). És traduït d'Estienne (1564, p. 78, chapitre 26), Pommier: «Le pommier vient en tout air, et ayme la terre grasse, noire et humide.» Aquest fr. aire 'àrea, airola, tros de terra de conreu' és traduït erradament per «ayre» (un mot fantasma doncs amb aquest significat, que per fortuna no ha passat a cap diccionari). S'hi ha afegit «de terra» per aclarir-ne el significat i es fa homònim del genuí «ayre» que trobem per exemple al foli anterior: «Lo pruner sufreix lo ayre fret y la terra humida y arenosa» (f. 53v).

brivant 'brivall' "Per guardar-los [els ciurons] que los passatgers y brivants no se'ls menjen, convé ruixar-los sinch matins abans que lo sol hisque» (f. 84r). El mot no el trobem recollit al DCVB, i al DECat (II: 246a.44) s'indica que apareix en el Diccionari Esteve-Belvitges-Julià de 1803-1805, amb la indicació de mot antic, i en efecte el tenim en el llibre del Prior, però potser enlloc més. Al Diccionari Fabra i després al Diccionari de l'IEC, l'hi trobem com a mot secundari que remet a brivall o amb el significat de 'nen'.

orifice 'orifici' (f. 108v). Un segon cas de traducció servil i d'un gal-licisme segurament espuri: tradueix un orifice del text francès (Estienne i Liébault, 1597: 727). D'aquest cas cap diccionari en parla, i segurament fan bé, per tal com aquests mots cultes presos del llatí en català acaben regularment amb -i (benefici, prefaci, etc.). Però crida l'atenció que en l'escrit aprovatori del començament, signat per fra Thomas Roca, del monestir de Santa Caterina de Barcelona, que lloa Agustí dient que «les coses singulars i de pràctica quals són aquestes, més 
acertat y millor és lo empírich que lo artifice» (per artifici), i aquí no podem dir que es tracta de la influència directa del francès.

secaresa (f. 106r). En l'apartat dels Secretes titulat «Discurs breu sobre la invenció, naturaleza, facultat, differències y necessitat del vi» observem una traducció literal de l'apartat que Estienne i Liébault (1597: 720) titulen «Discours passager sur l'invention, nature, facultez, differences et necessité du vin» i la frase francesa «pour empescher la continue seicheresse des parties solides» es tradueix per «per empedir la contínua secaresa de las parts senceras». Però també hi llegim sequedat (f. 77v). No deu ser casual que quan redacta de pròpia mà fa servir sequedat mentre que quan apareix secaresa és quan tradueix del francès.

Aire (de terra), brivant, orifice no apareixen ni al DCVB ni a l'extens recull de gal-licismes de Montserrat Barri (1999), treball en què es tenen en compte els Secrets de Miquel Agustí, però sí que hi apareix secaresa, possiblement perquè ha estat comentat per Coromines com un «gal-licisme rossellonès intolerable». Miquel Agustí inventa en alguns casos uns fantasmes de mots que no han arribat ni a mots fantasma, perquè són fruit espuri d'una traducció poc hàbil.

Si es té en compte que Agustí tragué molt dels llibres francesos d'Estienne ens podem explicar igualment construccions estranyes en català com la d'endossar el pronom personal davant del verb sense cap necessitat, un cop més el francès de les fonts deturpa l'estil d'Agustí: «la terra reposada ella produyrà roures, alzines, melcoratges, cardons» (f. 77r). Si bé doncs aquestes petges de gallicismes tenen la causa en l'obra francesa que n'és la font principal, pel que fa als castellanismes la raó no pot ser aquesta tenint en compte que no hi ha cap indici que ens indiqui una font castellana. No es pot tractar doncs de formes al·loglotes llibresques sinó més aviat de mots presents en el català parlat de l'època (Veny, 1978). Només n'esmentarem un cas: embriaguès (108v.30, 108v.33) és un castellanisme evident (en català antic era embriaguea) que no té a veure amb la traducció del francès (ebriété, 727) sinó que l'hem d'atribuir a una forma oral que corria en temps d'Agustí.

A Estienne i Liébault (1597: 727) llegim: «l'ebriété [...] rend les personnes insensées et si grands causeurs qu'ils ne se peuvent taire, ni rien celer» [= l'embriaguesa fa que les persones siguin insensates i xerraires, que no puguin callar ni amagar res]. I Agustí tradueix: «la embriaguès [...] torna les persones incensades, ni poden parlar, ni tenir res amagat» (108v.31).

Més enllà del lèxic, sembla evident que hi ha una traducció fracassada: la frase francesa ni rien celer significa que '[els embriacs] no poden amagar res', és a dir l'embriaguesa fa ser indiscret, no pas que «[no tinguis] res amagat». L'acarament d'aquests dos fragments ens introdueix en una qüestió que caldrà tenir en compte en l'edició crítica i que ara no és el moment de tractar: la dels errors de traducció que desvirtuen el text.

\section{Mots genuïns no literaris}

Si per una banda l'estil d'Agustí no és el més interessant des del punt de vista lingüístic i alguns del mots i construccions que fa servir són del tot calcs de traduc- 
ció, per una altra, els Secrets són una mina en relació amb la història del lèxic català genuí. La seva posició allunyada de la intenció literària té aquest vessant positiu, la de recollir termes dialectals ben genuïns que pel fet de ser locals no han tingut la sort de córrer pels textos literaris. Hi veiem, en efecte, el testimoni de mots dialectals particulars del nord-est del domini lingüístic com el rantell 'mosquit' empordanès (f. 193v) o el parpellol 'papallona' rossellonès (f. 194v), un possible occitanisme. Trobem també en Agustí el mot escaucell 'clot que se fa al voltant del cep, forma propera a l'occità escaucèl que després s'ha monoftongat en escocell, la forma actual (com la forma verbal derivada escocellar 'fer clot entorn del cep'), mot típicament rossellonès del qual el DCVB només dóna una citació històrica, la d'Agustí.

Un dels camps en què òbviament més rendiment pot donar l'explotació lingüística dels Secrets és el dels noms de plantes, de fruits i d'arbres. En donarem uns pocs exemples:

alberge, albergener 'mena de préssec'. Mot d'origen àrab del qual la primera documentació que coneixem és del 1539 i la segona aquestes dues referències dels Secrets: «per confitar totas maneras de fruytas grossas enteras, com són codonys, peres, pomes, alberges y albercochs» (f. 136r); «Pot-se empeltar d'esta manera entre fusta y escorça lo albrecoque, pomer, albergener, preseguer, ametller, figuera, castanyer, perer, pruner» (f. 66v). Present avui en el domini occidental (DCVB; DECat, s. v. préssec; ALDC, vol. V, mapes 1166 i 1168) en la forma auberge o bé aubergi, no tenim notícia que avui es conegui al nord-est del domini lingüístic però segurament hi devia existir, per l'ús que en fa Agustí i perquè a l'Empordà s'hi ha recollit al primer quart del segle xx poma alberge (DCVB, Llofriu), i pel fet (possible) que passà al Llenguadoc i d'aquí a Rabelais (DECat, IV: 798). Agustí dóna un suport important a la idea que l'àrea geolingüística d'alberge devia ser molt més extensa al seu temps.

arbre poll 'pollancre'. Apareix tres vegades en el nostre text, i no hi ha ni la forma simple poll (< ll. POPULus), que avui en rossellonès és pull, ni altres significants derivats com pollancre, formes aquestes totes dues més generals en català que no pas arbre poll. Podem afirmar que és un mot emblemàtic de la procedència banyolina de Miquel Agustí i marcadament dialectal, ja que no es troba pràcticament en cap altre parlar que el de Banyoles i el de l'Alt Empordà (ALPO, mapa 418 «peuplier»; ALDC, vol. V, núm. 1200: pollancre). A més, la primera vegada que es recull en un diccionari és en la forma arbre poll: es tracta del Thesaurus Puerilis d'Onofre Pou (1a edició: 1575), personatge de les comarques gironines («Gerundensi Artium Doctore») i que estigué instal-lat, com Agustí, a Perpinyà fent-hi de rector $\mathrm{i}$ de professor a la universitat $\mathrm{i}$ del qual sabem que introduí en la seva obra un bon nombre de formes dialectals del nord-est, del seu país d'origen.

caireta 'guixa'. DCVB en dóna només dues citacions antigues: una de 1523 i l'altra dels Secrets (f. 79v). És un terme que en els nostres temps s'usa a la Garrotxa (DCVB), es troba també en la monografia local de Joan Ramon Inglada, Els masos de l'Armentera (2002: 71), on a l'apartat dedicat a la vida quotidiana del segle XVII fa una llista extreta de documents que no especifica d'allò que es con- 
reava en aquestes terres entre el Baix i l'Alt Empordà i hi anota les «cairetes». No apareix, però, en el complet recull de termes dialectals El parlar de la Garrotxa de Joaquim Monturiol i Eloi Domínguez (2001).

Pel que fa a dent de ca (f. 145r), segurament la liliàcia Erythronium denscanis L. (fr. dent-de-chien, cast. diente de perro), nom que ja en llatí tenia la mateixa motivació, els diccionaris històrics només registren aquesta empremta antiga, l'ús en el llibre d'Agustí, sense cap altra citació històrica (DCVB), i amb el component $c a$ que és mot comú encara avui en rossellonès.

Els pocs exemples que aquí ara aportem volen posar en relleu la importància dels Secrets per a la història dels mots, alguns dels quals tenen com a única referència antiga, que coneguem, el llibre d'Agustí. També hem indicat que s'ha de fer l'acarament dels fragments traduïts i esbrinar amb atenció si el mot estudiat és només llibresc i circumstancial o bé es tracta d'un mot d'ús habitual, dialectal o no.

Després dels Secrets d'Agustí, amb prou feines passada una dècada, el llibre més interessant d'agricultura escrit en terres de parla catalana és l'Agricultura práctica de Francesc Gilabert, imprès a Barcelona el 1626, a la llista d'autors de referència del qual no apareix Agustí, però en canvi sí que hi ha Alonso de Herrera. Ens situem, doncs, en una altra línia de la tradició de les obres agronòmiques. El llibre de Gilabert té un objectiu clarament tècnic i ja no s'interessa per la cultura erudita ni pel recull poc o gens garbellat de textos anteriors. Malgrat aquest avenç que representa l'obra de Gilabert en els textos agronòmics, el llibre d'Agustí continuarà sent molt reeditat, sempre en castellà, i ha arribat a ser present en algunes llars pageses fins al segle xx. Què representaven cadascuna d'aquestes obres, tan distintes, en el seu context social i econòmic, $i$ en què es diferenciaven els lectors de cada obra si és que eren diferents? Cal avançar més en l'estudi històric i filològic d'aquesta tradició textual dels llibres agronòmics, encara a les beceroles, i posar llum a les xarxes en què s'emmallen.

\section{Referències bibliogràfiques}

Agustí, M. (1617). Llibre dels secrets d'agricultura, casa rústica i pastoril. Dues edicions facsímils: Barcelona: Altafulla, 1988, amb estudis preliminars de L. Argemí, J. Garriga, M. Prats, A. Rossich i A.-J. Soberanas; Vilafranca del Penedès: Andana, 2007, amb pròleg d'Emili Giralt i introducció de Xavier Luna-Batlle.

ALDC = VenY, J.; Pons, L. (2010). Atles lingüístic del domini català, vol. V: 10. Indústries relacionades amb l'agricultura, 11. Els vegetals. Barcelona: Institut d'Estudis Catalans.

ALPO = GuIter, E. (1966). Atlas Linguistique des Pyrénées Orientales. París: Centre National de la Recherche Scientifique.

Argemí, L. (1985). «Agronomía y revolución agraria en España (1750-1820)». A: Lluch, E.; Argemí, L. Agronomía y fisiocracia en España (1750-1820). València: Institución Alfonso el Magnánimo, 1-43.

Baranda, C. (1989). «Ciencia y humanismo: la Obra de agricultura de Gabriel Alonso de Herrera (1513). Criticón, 46, 95-108.

BARri, M. (1999). Aportació a l'estudi dels gal-licismes del català. Barcelona: Institut d'Estudis Catalans. 
Cifuentes, L. (2001). La ciència en català a l'Edat Mitjana i el Renaixement. Barcelona: Edicions de la Universitat de Barcelona.

DCVB = Alcover, A. M.; De BorJa Moll, F. (1930-1962). Diccionari català-valenciàbalear (2a ed. 1975-1977).

DECat = COROMINES, J. (1980-2001). Diccionari etimològic i complementari de la llengua catalana. Barcelona: Curial/La Caixa.

Estienne, Ch. (1564). L'Agriculture et Maison rustique. París: Jacques Dupuy. <https:// archive.org/details/lagricultureetma00esti>.

Estienne, Ch.; LiéBault, J. (1597). L’Agriculture et Maison rustique. Ginebra: Gabriel Cartier. <http://www.e-rara.ch/doi/10.3931/e-rara-6831>.

Gilabert, F. (1626). Agricultura práctica con la qual puede uno llegar a ser perfecto agricultor en lo mas necessario para la vida humana en qualquier tierra que estuviere. Barcelona: Sebastián de Comellas.

Giralt, E. (2002). «Les fonts del Llibre dels secrets de agricultura de fra Miquel Agustí (1617)». A: Negro Acedo, L. (ed.). Mélanges offerts à Charles Leselbaum. París: Éditions Hispaniques, 327-339.

- (2008). «El conreu de la vinya». A: Giralt, E. (dir.). Història agrària dels Països Catalans: III Edat Moderna, Barcelona: Publicacions de la Universitat de Barcelona.

Goudin, H. (2001). Olivier de Serres, science, expérience, diligence en agriculture au temps de Henri IV. Arles: Actes Sud.

Herrera, A. de [1513]. Agricultura general, edición crítica de Eloy Terrón. Madrid: Ministerio de Agricultura, 1996.

IngLADA, J. R. (2002). Els masos de l'Armentera. Figueres: Gràfiques Canigó.

Lieutaghi, P. (2001). «Le grand ménage des savoirs paysans». A: Olivier de Serres. Le Théâtre d'agriculture et mesnage des champs. Arles: Actes Sud, 7-54.

LunA-BAtLle, X. (2004). «Variació històrica i dialectal dins Els secrets d'agricultura (1617) de Miquel Agustí». Estudis de llengua i literatura catalanes XLIX, «Miscellània Joan Veny» 5, 37-51.

- (2011). Edició de Libre de plantar vinyes e arbres... Tractat d'agricultura del s. XV. Barcelona: Publicacions de l'Abadia de Montserrat.

-(2013). «El Llibre dels secrets d'agricultura, casa rústica i pastoril (1617) de Miquel Agustí: un llibre no del tot obert». Manuscrits, 31, 65-87.

Martí Escayol, M. A. (2012 [2008]) «El manuscrit Esp. 291 i el manuscrit BC 754 com a fonts del Llibre dels secrets de agricultura de Miquel Agustí». A: MARTí EsCAYOL, M. A. (ed.). De Re Rustica. Vilafranca del Penedès: Edicions i propostes culturals Andana, 39-55.

Mizauld, A. (1578). Le jardinage. Ginebra: Jean Lertout.

Monturiol, J.; Domínguez, E. (2001). El parlar de la Garrotxa. Olot: Ràdio Olot.

NúÑEZ, L. P. (2007-2008). «Ediciones e historia textual del Libro de los secretos de agricultura de Miguel Agustín». Butlletí de la Reial Acadèmia de Bones Lletres de Barcelona, LI, 199-223.

Saltini, A. (1979). Storia delle scienze agrarie. Bolonya: Edagricole.

Serres, O. de (2001 [1600]). Le Théâtre d'agriculture et mesnage des champs. Arles: Actes Sud (d'acord amb la de 1804-1805)

VenY, J. (1979 [1962]). «Sobre els castellanismes del rossellonès». A: VENY, J. Estudis de geolingüística catalana. Barcelona: Edicions 62.

—(2001 [1988]). Llengua i entorn natural. Barcelona: Edicions 62. 